\title{
CHARACTERIZATION OF TRACE METAL SPECIES AND MEASUREMENT OF TRACE METAL STABILITY CONSTANTS BY ELECTROCHEMICAL TECHNIQUES
}

\author{
R. ER.NST,* H. E. Allen†‡ and K. H. Mascy \\ Environmental Chemistry Laboratory, Department of Environmental and Industrial Health. \\ School of Public Health. The University of Michigan, Ann Arbor, MI 48104. U.S.A.
}

(Received 23 May 1974)

\begin{abstract}
Differential pulse polarography and differential pulse anodic stripping voltammetry were used to determine copper, lead, cadmium and zinc complexes of relevance to environmental conditions. The dependency of peak current on $\mathrm{pH}$ and alkalinity was interpreted in terms of the variation in the metal species present. Stability constants of copper and lead complexes with carbonate were determined from the magnitude of the shift of peak potential using the method of Lingane. Inclusion of the transfer coefficient, calculated from the peak half-width for electrochemically irreversible systems, was used to determine the stability constant. By using both electroanalytical techniques, the investigator validates the correctness of his results without needing to rely on prior determinations of the stability constant for verification.
\end{abstract}

\section{INTRODLCTION}

Present awareness of the importance of trace metals in aquatic systems has prompted increased activity in both the development of trace analytical techniques and the study of the physicochemical behavior of low levels of metals. Although the majority of water quality standards specify, and environmental studies have measured only the total concentration of a trace metal, it has become apparent that the chemical form of the metal must be known to permit an accurate interpretation of both its biological effects and geochemical reactions. Prediction of trace metal environmental levels, forms, and transformations requires the development of mechanistic models which are based on equilibrium constants of metal complexes.

Methods for the determination of stability constants have been reviewed by Martell and Calvin (1952), Rossotti and Rossotti (1961) and Beck (1970). These books deal with many analytical procedures and their underlying theoretical bases. However, the examples used are almost exclusively simple systems generally containing a single metal and a single wellcharacterized ligand, both present at levels much higher than those in the environment. Application of these techniques to the study of environmentally significant complexation reactions has been carried out primarily by soil chemists concerned with metalhumic acid and metal-fulvic acid reactions. The techniques which have received the most use are potentio-

* Present address: Department of Chemistry, University of Lausanne, Lausanne, Switzerland.

† Present address: Department of Environmental Engineering, Minois Institute of Technology, Chicago, IL 60616, U.S.A.

¥ To whom correspondence should be addressed. metric titration, Job's continuous variation technique and ion-exchange equilibrium (Schnitzer and Khan, 1972; Stevenson and Ardakani, 1972). Recent work by Cheng. Patterson and Minear (1975) has utilized the ion-exchange equilibrium method for determining the stability constant of various metals complexed with the soluble portion of sewage. Other investigators (Bradford, 1973; Stumm and Bilinski, 1973) have employed anodic stripping voltammetry for the determination of the stability constants of hydroxide and carbonate complexes of zinc and lead. These investigations were conducted to ascertain those complexes which predominate under environmental conditions.

We have investigated the use of both differential pulse polarography (DPP) and differential pulse anodic stripping voltammetry (DPASV) for the assessment of trace metal complexation. The application of these techniques to environmental measurements is presented here while the electrochemical basis for these results will be discussed elsewhere (Ernst, Allen and Mancy, 1974).

\section{POLAROGRAPHIC DETERMINATION OF STABILITY CONSTANTS}

Although polarography has been widely used for the quantitative determination of metals in the aquatic system, utilization of this technique for the determination of stability constants of these metals with naturally occurring ligands has been extremely limited. The detection limit for normal polarography does not permit analysis at the level at which metals normally occur in the environment. If samples are concentrated, shifts in chemical equilibria will result. Newer electroanalytical techniques such as pulse polarography and anodic stripping voltammetry have 

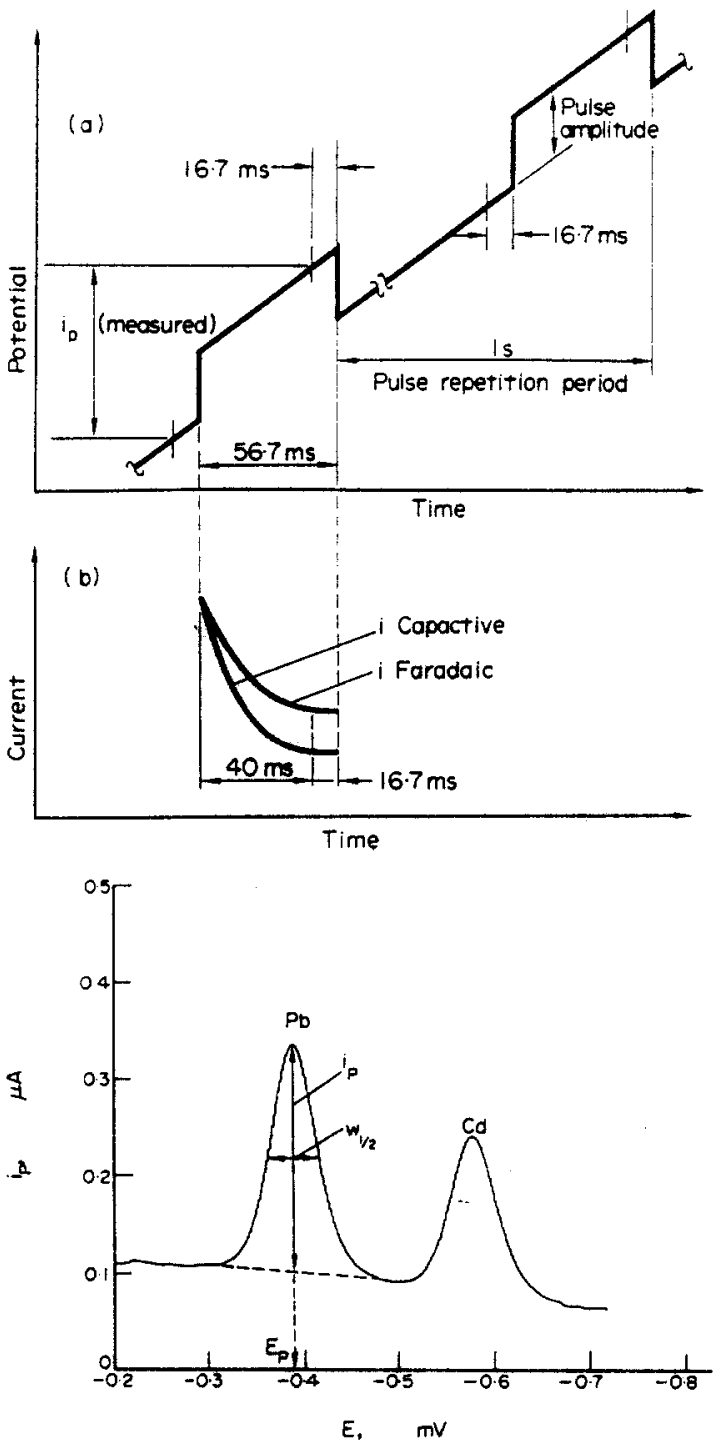

Fig. 1. Differential pulse voltammetry (a) excitation waveform. (b) resulting current-time behaviour and (c) differential pulse polarogram for $\mathrm{Pb}^{2+}$ and $\mathrm{Cd}^{2+}$ in $0.1 \mathrm{M} \mathrm{KNO}_{3}$ showing peak current $\left(i_{p}\right)$, peak potential $\left(E_{p}\right)$, and halfpeak width $\left(W_{1 / 2}\right)$. Measurement conditions were $2 \mathrm{mV} \mathrm{s}^{-1}$ scan rate and $25 \mathrm{mV}$ pulse amplitude.

sufficiently low detection limits that direct measurement of environmentally significant levels of trace metals is feasible.

The application of DPP and DPASV to the measurement of trace metals in natural waters has been discussed by Osteryoung and Osteryoung (1972) and Siegerman and O'Dom (1972), respectively. For differential pulse measurements the potential wave form shown in Fig. 1(a) is applied to the electrode. Application of the pulse causes a large increase in the flow of both capacitive and faradaic currents. Since the capacitive current decays more rapidly than the faradaic current, the measured current at the end of the pulse will be almost exclusively faradaic [Fig. 1(b)]. It is due to this virtual elimination of the capacitive current that pulse techniques are able to achieve detection limits approximately two orders of magni- tude lower than by the corresponding d.c. technique. In addition. the peak eurrent $\left(i_{p}\right)$ and the peak potential $\left(E_{p}\right)$ can be easily determined from the nearly symmetrical peaks obtained by DPP or DPASV [Fig. 1(c)]. which will facilitate measurement.

Early workers observed that the d.c. polarographic half-wave potential $\left(E_{12}\right)$ could vary as the medium was altered in chemical composition. Heyrovsky and Ilkovic (1935) explained such shifts as being a result of complexation. Lingane (1941) was the first to quantitatively treat the phenomena. For the reaction:

$$
M^{n+}+j L \rightleftarrows M L_{j}^{n+}
$$

having the formation constant

$$
\beta_{j}=\frac{\left[M L_{j}^{n+}\right]}{\left[M^{n+}\right][L]^{j}}
$$

he developed the following relationship between the shift in potential and the equilibrium ligand concentration:

$$
\begin{aligned}
\Delta E_{1 / 2} & =\left(E_{1 / 2}\right)_{s}-\left(E_{1 / 2}\right)_{c} \\
& =\frac{2.303 R T}{n \mathscr{F}} \log \beta_{j}+j \frac{2.303 R T}{n \tilde{F}} \log [L]
\end{aligned}
$$

where $\left(E_{1 / 2}\right)_{s}$ is the half-wave potential of the simple, uncomplexed metal ion, $M^{n+} ;\left(E_{1,2}\right)_{c}$ is the half-wave potential of the metal in the presence of the ligand concentration $[L] ; n$ is the number of electrons exchanged in the reduction process; and (2.303RT) $n \mathscr{F}$ ) is a constant having the value of 0.0591 at $25^{\circ} \mathrm{C}$.

The following assumptions have been made in the derivation of the Lingane equation.

(1) The diffusion coefficient of the complex must be the same as that of the simple metal ion.

(2) The complex which is formed must be electrochemically labile.

(3) The ligand concentration at the electrode surface must be equal to the bulk concentration.

(4) The reduction of the metal must be electrochemically reversible.

(5) A single complex must predominate over a wide range of ligand concentrations.

These conditions have been discussed in detail by Crow (1969) and Heyrovsky and Kuta (1965).

Frequently, the condition of having a predominant complex is not fulfilled. Consequently, when the shift in half-wave potential is plotted versus the logarithm of the ligand concentration, a curve results rather than the straight line predicted by the Lingane equation. The method of DeFord and Hume (1951) has been used to interpret these curves as a summation of overlapped Lingane relationships and allows the individual formation constants to be ascertained.

Many ligand-metal systems are not electrochemically reversible and therefore are not amenable to treatment by the Lingane method. However, these irreversible systems may be of considerable practical importance and it is. therefore, important to have methods capable of studying them. 
The most common method used for irreversible systems is the indicator method introduced by Schwarzenbach and co-workers (Ackerman and Schwarzenbach, 1952; Schwarzenbach, Gut and Anderegg 1954). A labile complex of the ligand with another metal is required as an indicator. It must be reversibly reduced at a more positive potential than the half-wave potential of the metal under investigation and the two complexes must have similar stability constants. The stability constant can be determined from comparison of the current measured for the reversibly reduced metal, first in the absence of ligand, then in the presence of both the ligand and the irreversibly reduced metal. As many environmentally significant ligands would be expected to form irreversibly reduced complexes with most metals, this procedure would be unusable.

The shift in half-wave potential for an indicator complex has been used by Ringbom and Eriksson (1953) and Eriksson (1953) to estimate the stability constant of irreversible systems. However, the necessity of the rapid reaction of the reduced metal with the ligand and the need for chemical equilibrium to be established almost instantaneously are very strong limitations of the technique (Crow and Westwood, 1965).

Subrahmanya (1960) used a modified version of the Lingane equation to account for the irreversibility of the electrode process. This treatment which is based on the work of Tamamushi and Tanaka (1949) results in the following equation for an irreversible reduction process:

$$
\begin{aligned}
\Delta E_{1 / 2} & =\left(E_{1 / 2}\right)_{s}-\left(E_{1 / 2}\right)_{c} \\
& =\frac{2.303 R T}{\alpha n \mathscr{F}} \log \beta_{j}+j \frac{2.303 R T}{\alpha n \mathscr{F}} \log [L]
\end{aligned}
$$

where the transfer coefficient $\alpha$ is the fraction of the total applied potential which favors the forward reaction.

Since the slope of the d.c. polarographic wave is a measure of the reversibility of the process, measurement of the wave at $\frac{1}{4}$ and $\frac{3}{4}$ of its maximum value permits the determination of the value of $\alpha$ from the relationship

$$
E_{3 / 4}-E_{1 / 4}=-\frac{0.0563}{2 n}
$$

For DPP the peak half-width was shown by Parry and Oldham (1968) to be dependent on both the amplitude of the applied pulse and the reversibility of the reduction. When using small values for the pulse amplitude the peak half-width $\left(W_{1 / 2}\right)$ is given by the equation:

$$
W_{1 / 2}=3.52 \frac{R T}{\alpha n F}
$$

from which the value of $\alpha$ can be evaluated.

\section{EXPERIMENTAL}

A Princeton Applied Research polarograph Model 174 was used in the differential pulse mode. A Houston Instru- ments Omnigraphic Model 2000 recorder was used for recording the polarograms. For DPASV a Metrohm E 410 microfeeder and a capillary cylinder were used to provide a $0.83 \mathrm{~mm}$ (4 division) hanging mercury drop. For DPP, a PAR Model 172 Drop Timer was used to dislodge the mercury drops. All potentials were measured at $25^{\circ} \mathrm{C}$ vs a saturated calomel electrode.

The alkalinity of samples was fixed at $10^{-3} \cdot 10^{-2}$, or $10^{-1}$ equiv $1^{-1}$ by adding the required amount of $\mathrm{NaH}$ $\mathrm{CO}_{3}$. The $\mathrm{pH}$ could then be controlled and adjusted as desired by equilibrating the sample with the appropriate partial pressure of $\mathrm{CO}_{2}$. The carbonate concentration at each alkalinity and $\mathrm{pH}$ was calculated using the equations presented by Roberts and Allen (1972).

Stock solutions, $10^{-3} \mathrm{M}$ in metal. were prepared by dissolving the required amount of reagent-grade metal nitrate and adjusting to $\mathrm{pH} 3$. All samples were $2.5 \times 10^{-6} \mathrm{M}$ with respect to the trace metal and, in addition to the $\mathrm{NaHCO}_{3}$, 0.1 moles $1^{-1} \mathrm{KNO}_{3}$ was added as a non-reactive supporting electrolyte.

For experiments with organic ligands, in addition to the previously named reagents. the required amount of $10^{-3} \mathrm{M}$ glycine or $500 \mathrm{mg} \mathrm{l}^{-1}$ humic acid ( $\mathrm{K} \& \mathrm{~K}$ Laboratories) was added.

Solutions were deaerated for $30 \mathrm{~min}$ prior to their initial measurement. Measurements were repeated to ensure that equilibrium had been attained. After further addition of ligand or lowering of the $\mathrm{pH}$ by increasing the partial pressure of $\mathrm{CO}_{2}$, generally only a short time was required to reattain equilibrium.

For DPASV the solution was mixed with a magnetic stirrer during the electrodeposition. The deposition was conducted with the instrument in the differential pulse mode so that a voltage excursion $+25 \mathrm{mV}$ from the deposition potential occurred once each second. The deposition potential was $200-300 \mathrm{mV}$ more cathodic than the peak potential so that the effect of the $25 \mathrm{mV}$ pulses on the amount of metal deposited was small. The deposition potentials were $-200 \mathrm{mV}$ for $\mathrm{Cu}^{2+},-800 \mathrm{mV}$ for $\mathrm{Pb}^{2+}$, $-750 \mathrm{mV}$ for $\mathrm{Cd}^{2+}$ and $-1200 \mathrm{mV}$ for $\mathrm{Zn}^{2+}$. Samples were electrolyzed for $100 \mathrm{~s}$ while the solution was stirred and for $20 \mathrm{~s}$ more under quiescent conditions. In the stripping step a $+25 \mathrm{mV}$ pulse was superimposed once each second on a voltage ramp which increased at 0.1 or $2 \mathrm{mV} \mathrm{s}^{-1}$. In the case of glycine and humic acid solutions for both DPP and DPASV, the voltage scan rate of $0.1 \mathrm{mV} \mathrm{s}^{-1}$ was used to permit measurement of the halfpeak width and the peak potential with increased precision.

The same conditions, but with both the sweep rate and the pulse being cathodic, were used for DPP.

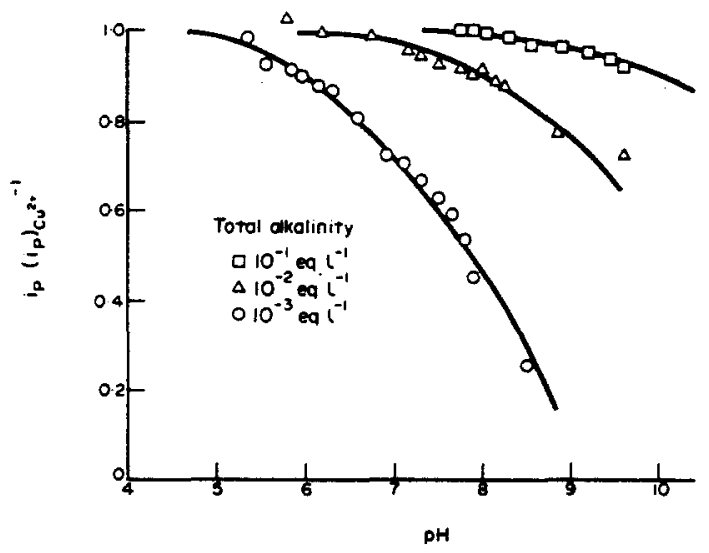

Fig. 2. Variation of DPP current as a function of $\mathrm{pH}$ and alkalinity for $2.5 \times 10^{-6} \mathrm{M}$ copper. Current has been normalized to that for $\mathrm{Cu}^{2+}$. 


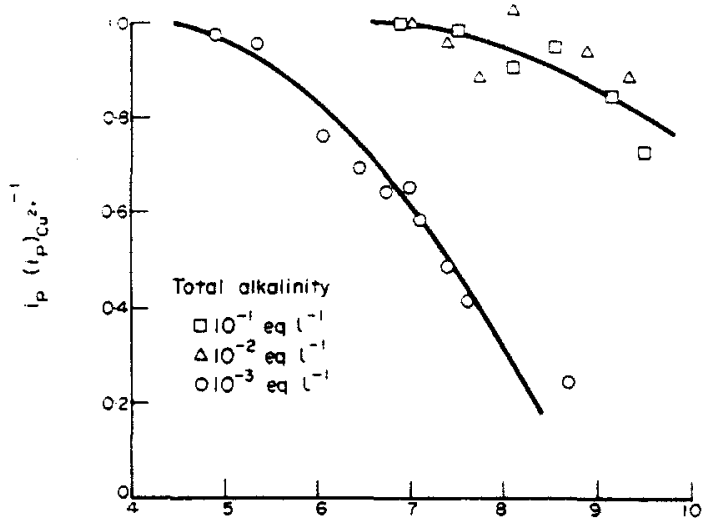

$\mathrm{pH}$

Fig. 3. Variation of DPASV current as a function of $\mathrm{pH}$ and alkalinity for $2.5 \times 10^{-6} \mathrm{M}$ copper. Current has been normalized to that for $\mathrm{Cu}^{2+}$.

\section{DEPENDENCE OF $i$, ON pH AND ALKALINITY}

A pH-dependent model for the chemical speciation of copper, zinc, cadmium and lead in seawater has been developed by Zirino and Yamamoto (1972). They considered the ligands $\mathrm{CO}_{3}^{2-}, \mathrm{HCO}_{3}^{-}, \mathrm{SO}_{4}^{2-}, \mathrm{Cl}^{-}$, and $\mathrm{OH}^{-}$at the levels occurring in seawater. Within the $\mathrm{pH}$ range $7-9$, the hydroxy and carbanato complexes and the free metals were the most important species except in the case of cadmium, where the high level of chloride in the seawater results in chloride complexes being dominant over the entire $\mathrm{pH}$ range considered. The increase in ASV signal resulting from lowering the $\mathrm{pH}$ of seawater from 8 to 5.5 was reported in support of the model.

To provide pertinent information regarding the effect of ligands on ASV, we have compared the electrodeposition step as measured by DPP to both the electrodeposition and stripping steps as measured by

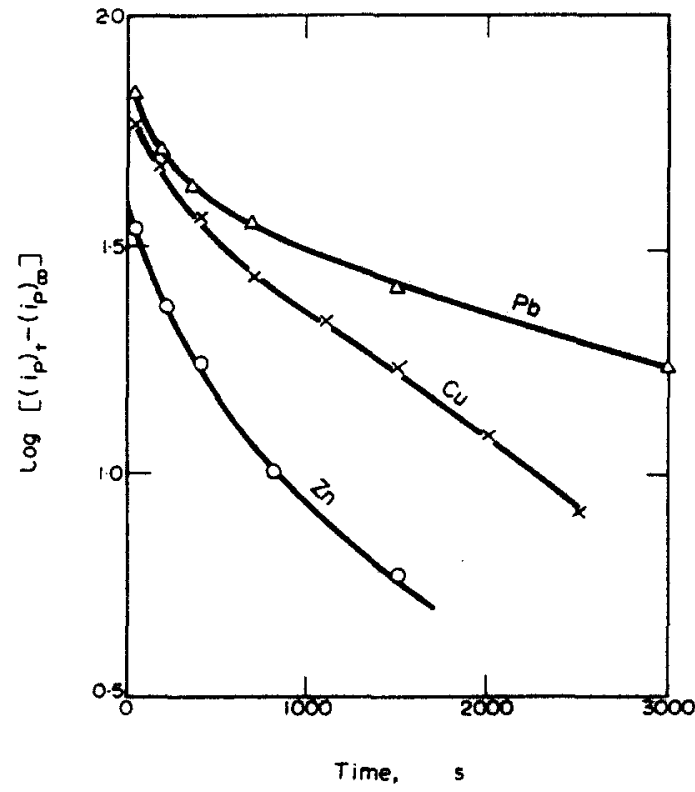

Fig. 4. Variation of DPP current as a function of time for $2.5 \times 10^{-6} \mathrm{M}$ copper, lead, and zinc. Total alkalinity was $10^{-3}$ equiv $1^{-1}$ and $\mathrm{pH}$ was approximately nine.
DPASV. Detailed experimental investigation in which both $\mathrm{pH}$ and carbonate have been independently varied is not available and. therefore, interpretation of ASV signals from environmental samples in terms of species rather than labile and non-labile components is not possible (Mancy, 1972).

For DPP measurements of copper, lead, cadmium and zinc solutions a maximum signal was obtained at low $\mathrm{pH}$ values where the hydrated metal ion was the dominant species. At higher $\mathrm{pH}$ values, the signal decreased but this decrease was less in solutions of high alkalinity. Typical results for the effect of $\mathrm{pH}$ and alkalinity on DPP are shown in Fig. 2. The decrease in signal at higher $\mathrm{pH}$ indicates the formation of insoluble species such as $\mathrm{Cu}(\mathrm{OH})_{2}, \mathrm{Zn}(\mathrm{OH})_{2}$, and $\mathrm{PbCO}_{3}$. Higher levels of carbonate appear to favor metal solubility due to formation of ion pairs such as $\mathrm{CuCO}_{3}^{\circ}$ and $\mathrm{PbCO}_{3}^{\circ}$, which favorably compete with solid species for the metals.

DPASV curves of $i_{p}$ vs $\mathrm{pH}$ were similar to those obtained for DPP. For example, the results for copper which are plotted in Fig. 3, exhibit a similar dependency of $i_{p}$ on $\mathrm{pH}$. However, for zinc and lead this dependency is greater for DPASV than for DPP. If there were no difference between DPASV and DPP data, this would indicate that the cathodic reaction is the controlling step. Since results by DPASV and DPP differ, the signal obtained by the DPASV measurement is dependent upon both the plating and the stripping steps. Present research in this laboratory (Twork, 1974) is directed toward the elucidation of the dependency of $i_{p}$ upon the chemical composition of the medium used in the stripping step.

Only qualitative interpretations were based on $i_{p}$ vs $\mathrm{pH}$ diagrams. Absolute measurements of current are complicated by slow precipitation and adsorption of dissolved or colloidal materials onto the cell. The slowness of the reaction at high $\mathrm{pH}$ and low alkalinity is indicated in Fig. 4.

\section{Copper}

Analysis of copper curves (Figs. 2 and 3) indicates that both hydroxide and the carbonate system are important in regulating the species of copper present. The importance of carbonate ions is shown most clearly in Fig. 2, where three independent, non-superimposed curves were obtained for the three alkalinities. At any $\mathrm{pH}$, the $\left[\mathrm{CO}_{3}^{--}\right]$is almost directly proportional to the total alkalinity. If only carbonate were important parallel curves displaced on the $\mathrm{pH}$ axis would be expected in Figs. 2 and 3. The fact that the DPP curves are not parallel indicates the contribution of the hydroxide ion in regulating copper speciation. This conclusion supports the equilibrium model of Zirino and Yamamoto (1972) who calculate that $\mathrm{Cu}^{2+}, \mathrm{CuCO}_{3}^{0}$ and $\mathrm{Cu}(\mathrm{OH})_{2}^{0}$ are the dominant copper species in solution. Based on previous work in this laboratory (Mancy and Allen, 1974) an equilibrium distribution diagram for copper was calculated (Fig. 5), and carbonate and hydroxide are both important. 

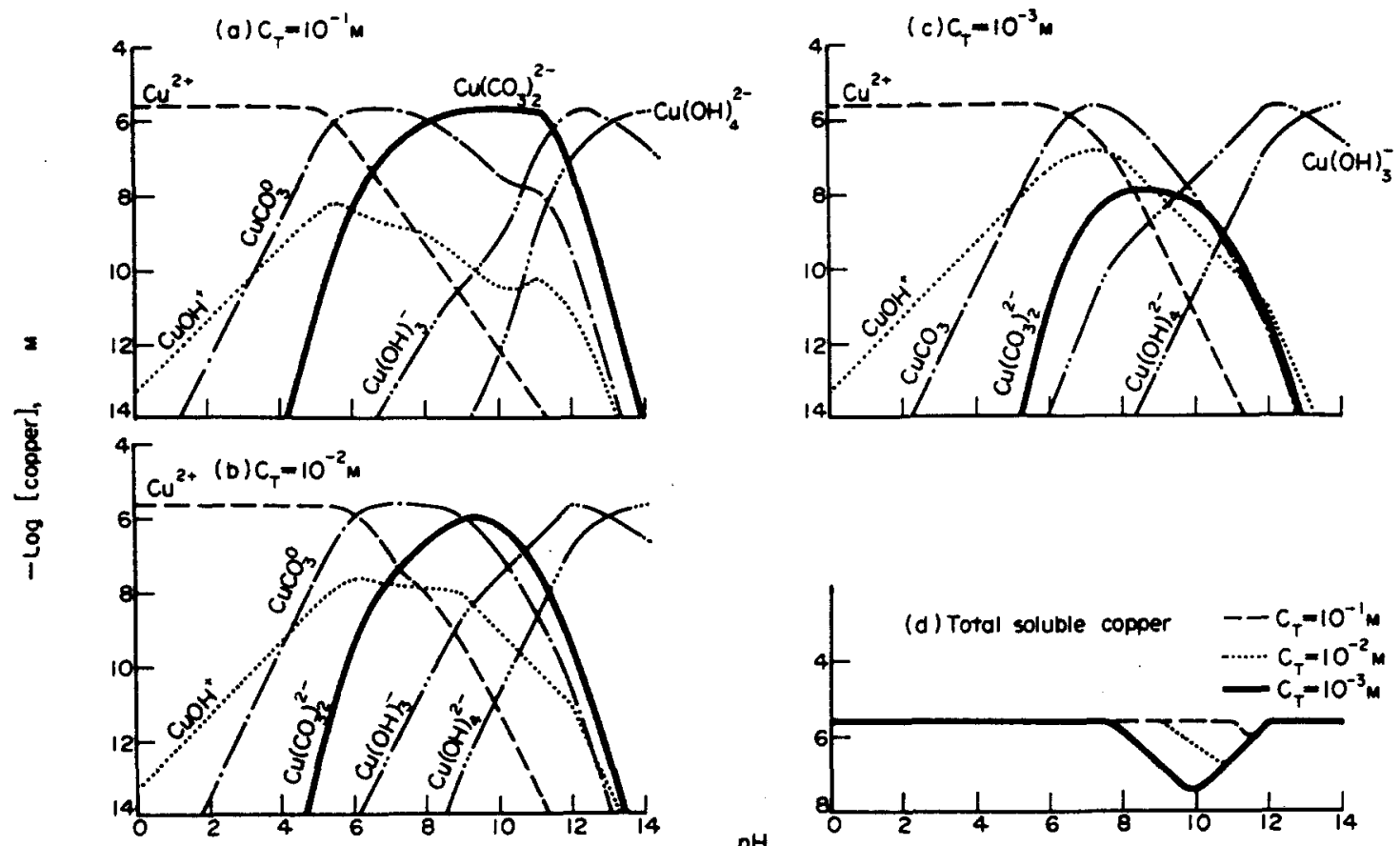

Fig. 5. Comparison of $\log$ copper vs $\mathrm{pH}$ diagrams for $2.5 \times 10^{-6} \mathrm{M}$ total copper where [total carbonate] $=$ (a) $10^{-1} \mathrm{M}$, (b) $10^{-2} \mathrm{M}$. or (c) $10^{-3} \mathrm{M}$. and (d) of log [soluble copper] vs pH for total carbonate concentrations of $10^{-1}, 10^{-2}$ and $10^{-3} \mathrm{M}$.

Lead

The plots of $i_{p}$ vs $\mathrm{pH}$ for the lead system, shown in Fig. 6, are similar to those for copper. However, the three lead curves tend to be more parallel than those for copper shown in Fig. 2. We can infer, at least qualitatively, that carbonate is much more important to lead speciation than is hydroxide. For a given $\mathrm{pH}$, high alkalinity is associated with high current value which is an indication of increased solubility. Increased alkalinity results in decreased diminution of signal due to lead precipitation, which cannot be $\mathrm{PbCO}_{3}$. This conclusion contradicts the model for lead solubility in natural waters proposed by Hem and Durum (1973). They indicated that while $\mathrm{Pb}(\mathrm{OH})_{2}$ was the solid phase present at high $\mathrm{pH}$, solid $\mathrm{PbCO}_{3}$ was present at lower $\mathrm{pH}$. Their equilibrium solubility calculations in the $\mathrm{pH}$ range $5-9$ show lower soluble lead concentrations at higher total carbonate levels. An explanation for the discrepancy between our experimental data and their calculation might be the omission of the $\mathrm{PbCO}_{3}^{0}$ ion pair from the model. In the model proposed by Zirino and Yamamoto (1972), the $\mathrm{PbCO}_{3}^{\circ}$ ion pair was predicted to be the dominant soluble species over the $\mathrm{pH}$ range considered. Recent work by Bilinski and Stumm (1973) supports the model of Zirino and Yamamoto.

\section{Zinc}

Zinc curves, for the three values of alkalinity, are almost superimposed and are strongly $\mathrm{pH}$ dependent above $\mathrm{pH}$ 7.5. This is shown in Fig. 7. The decrease in signal is assumed to be due to the precipitation of zinc hydroxide. In the $\mathrm{pH}$ range between 8 and 9 , the peak potential shifts towards more cathodic values. At pH greater than 9 a second peak appears and its signal increases with increasing $\mathrm{pH}$. This second peak, which occurs at a potential more cathodic than the first, results from the direct electrochemical reduction of a non-identified zinc complex at the electrode surface.

\section{Cádmium}

Cadmium undergoes minimal complexation or precipitation in the media tested. There was less than $10 \%$ decrease in peak current at any $\mathrm{pH}$ or alkalinity investigated. The results from the model of Zirino and Yamamoto (1972) are not directly comparable with our experimental results since chloride, which was included in their model, forms strong cadmium complexes. In this model, neglecting the chloro-complexes, the hydrated cadmium ion predominates until

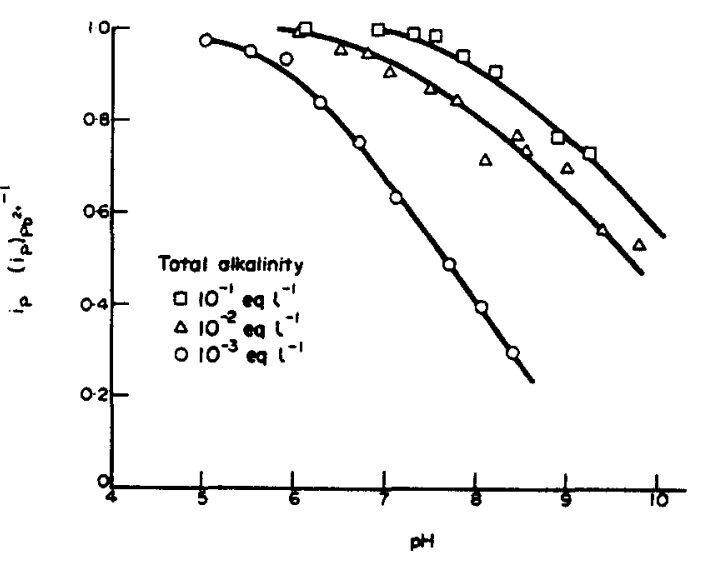

Fig. 6. Variation of DPP current as a function of $\mathrm{pH}$ and alkalinity for $2.5 \times 10^{-6} \mathrm{M}$ lead. Current has been normalized to that for $\mathrm{Pb}^{2+}$. 


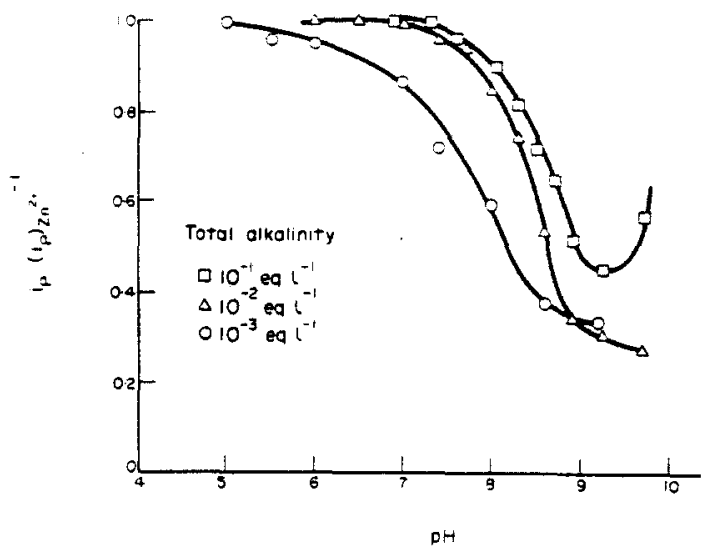

Fig. 7. Variation of DPP current as a function of $\mathrm{pH}$ and alkalinity for $2.5 \times 10^{-6} \mathrm{M}$ zinc. Current has been normalized to that for $\mathrm{Zn}^{2+}$.

$\mathrm{pH} \mathrm{9,} \mathrm{at} \mathrm{which} \mathrm{point} \mathrm{the} \mathrm{concentration} \mathrm{of} \mathrm{the} \mathrm{ion}$ pair $\mathrm{CdCO}_{3}^{0}$ equals that of $\mathrm{Cd}^{2+}$.

\section{DEPENDENCE OF $E_{p}$ ON INORGANIC LIGAND CONCENTRATION}

The data obtained from DPP and DPASV were further analyzed to explain the observed electrochemical results. When initially recording the voltammagrams, it was obvious that the peak potential varied as the $\mathrm{pH}$ was adjusted. This effect was pronounced at higher values of $\mathrm{pH}$ while at low $\mathrm{pH}$ values the potential was invariant. In addition, the peak potential at high values of $\mathrm{pH}$ was different for the various alkalinities.

\section{Lead}

When the peak potential was plotted vs the $\mathrm{pH}$, a regular pattern, such as that obtained for the lead carbonate system (Fig. 8), could be observed. The aforementioned effects appeared to be both regular and systematic. Since different curves were obtained for the different alkalinities, it was apparent that the shift in peak potential was not due solely to hydroxyl ion, but must also have been dependent upon carbonate.

The data for DPP presented in Fig. 8 have been replotted in Fig. 9 to show the peak potential as a function of carbonate concentration rather than as a function of $\mathrm{pH}$. The linear dependence indicates that a single carbonate complex of lead predominates from $\mathrm{pH} 6.5$ to 9.0 for all alkalinities studied. For DPASV a linear regression with the same slope as DPP is obtained but the intercept of the line is different. The difference is in agreement with prediction (Ernst et al., 1974).

Acid solutions, which contained no bicarbonate, were analyzed by DPP and DPASV to determine the value of the peak potential for the free metal ion. These values which were -375 and $-405 \mathrm{mV}$, respectively, were used in determining the shift in peak potential, $\Delta E_{p}$, resulting from complexation. The Lingane equation was used to calculate the number of ligands and the stability constant of the complex.

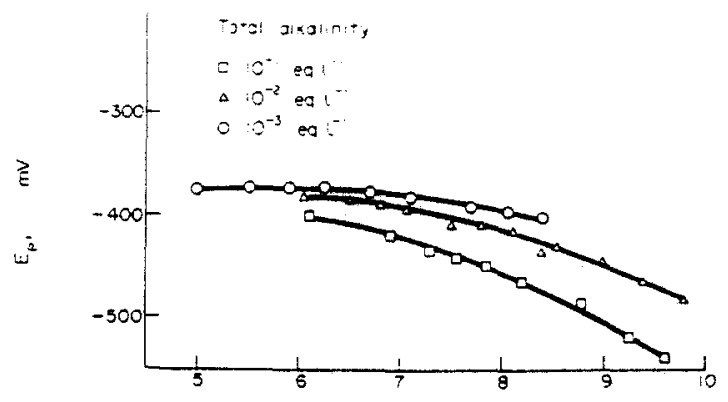

$\mathrm{oH}$

Fig. 8. Variation of DPP peak potential as a function of $\mathrm{pH}$ and alkatinity for $2.5 \times 10^{-6} \mathrm{M}$ lead.

To determine the stability constant for the leadcarbonate system, a line was fitted by inspection to the data shown in Fig. 9. At low carbonate concentrations insufficient ligand was present to cause appreciable complex formation. Thus, the slope in this region approaches zero. At high concentrations the points again deviate from the line, but this is due to an increase in slope indicating that a higher order complex becomes predominant. The slope and intercept of the line shown in Fig. 9 were computed by a least squares linear regression.

Both DPP and DPASV produced similar results for the ligand number as well as the stability constant (Table 1). The ratio of carbonate to lead was determined to be 1.07 from the DPP data and 1.06 from the DPASV data. Values for the logarithm of the sta. bility constant were 6.2 by DPP $( \pm 0.2$ S.E.) and 6.3 by DPASV $( \pm 0.4$ S.E.).

The method of Lingane is applicable only to reversible, diffusion controlled systems (Crow, 1969). If the system were not reversible, the same results could be

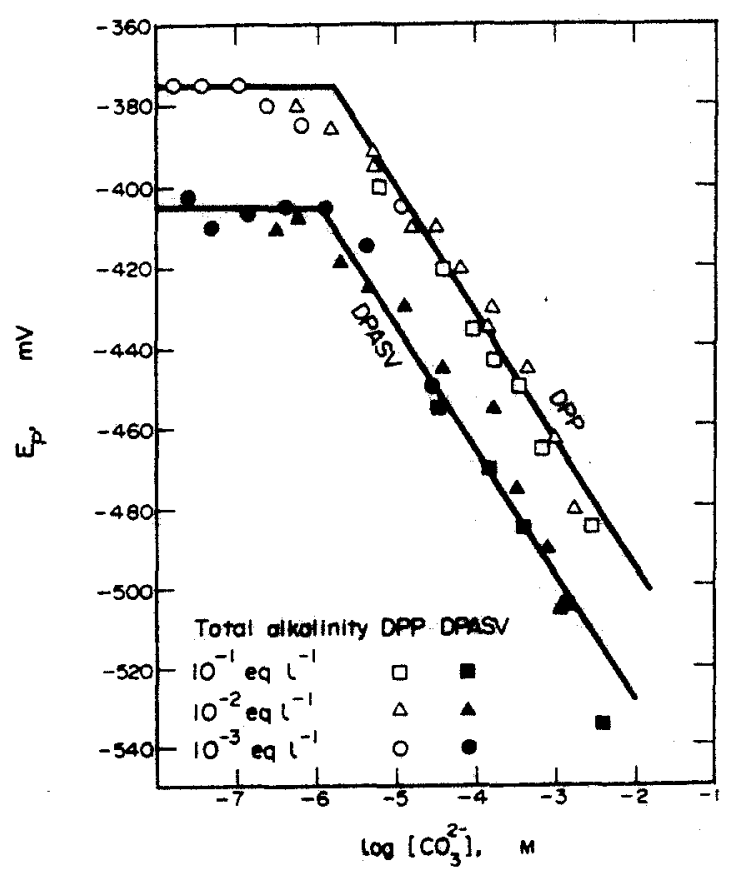

Fig. 9. Variation of DPP and DPASV peak potentials as a function of carbonate ion concentration for $2.5 \times 10^{-6} \mathrm{M}$ lead. 
Table 1. Summary of results for stability constant determinations by DPP and DPASV

\begin{tabular}{|c|c|c|c|c|c|c|}
\hline Metal & Ligand & Technique & $\begin{array}{l}\text { Number of } \\
\text { observations }\end{array}$ & $\begin{array}{c}\text { Transfer } \\
\text { coefficient } \\
\text { (x) }\end{array}$ & $\begin{array}{c}\text { Ligand } \\
\text { number* } \\
(j)\end{array}$ & $\begin{array}{l}\text { Logarithm } \\
\text { of } \\
\text { stability } \\
\text { constant* } \\
(\log \beta)\end{array}$ \\
\hline \multirow{3}{*}{$\mathrm{Pb}$} & \multirow{3}{*}{$\mathrm{CO}_{3}^{--}$} & DPP & 18 & Reversible & $1.07 \pm 0.05$ & $6.2 \pm 0.2$ \\
\hline & & DPASV & 14 & Reversible & $1.06 \pm 0.10$ & $6.3 \pm 0.4$ \\
\hline & & DPP & 19 & Reversible & $0.93 \pm 0.04$ & $5.7 \pm 0.2$ \\
\hline \multirow[t]{2}{*}{$\mathrm{Cu}$} & \multirow[t]{2}{*}{$\mathrm{CO}_{3}^{2-}$} & DPASV & 10 & Reversible & $0.99 \pm 0.04$ & $6.1 \pm 0.2$ \\
\hline & & DPP & 12 & Reversible & $1.63 \pm 0.09$ & $8.1 \pm 0.3$ \\
\hline \multirow[t]{2}{*}{$\mathrm{Cu}$} & \multirow[t]{2}{*}{$\mathrm{CO}_{3}^{2-}$} & DPASV & 5 & Reversible & $1.55 \pm 0.07$ & $8.2 \pm 0.2$ \\
\hline & & DPP & 8 & 0.79 & $1.24 \pm 0.04$ & $6.4 \pm 0.1$ \\
\hline \multirow[t]{2}{*}{$\mathrm{Cu}$} & \multirow[t]{2}{*}{ Glycine } & DPASV & 7 & 0.93 & $1.28 \pm 0.13$ & $5.9 \pm 0.5$ \\
\hline & & DPP & 5 & 0.50 & $1.69 \pm 0.04$ & $10.2 \pm 0.2$ \\
\hline \multirow[t]{2}{*}{$\mathrm{Cu}$} & \multirow[t]{2}{*}{ Humic acid } & DPASVt & - & Variable & 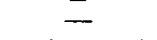 & 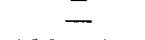 \\
\hline & & DPP & 4 & 0.50 & $2.98 \pm 0.04$ & $16.8 \pm 0.2$ \\
\hline \multirow[t]{2}{*}{$\mathrm{Cu}$} & \multirow[t]{2}{*}{ Humic acid } & DPASV+ & - & Variable & 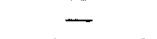 & - \\
\hline & & DPP & 6 & 0.76 & $1.14 \pm 0.06$ & $7.8 \pm 0.4$ \\
\hline \multirow[t]{2}{*}{$\mathrm{Pb}$} & \multirow[t]{2}{*}{ Humic acid } & DPASV & 6 & 0.61 & $0.66 \pm 0.03$ & $4.0 \pm 0.1$ \\
\hline & & DPP & 8 & 0.76 & $2.48 \pm 0.11$ & $14.3 \pm 0.5$ \\
\hline $\mathrm{Pb}$ & Humic acid & DPASV & 4 & 0.61 & $1.08 \pm 0.01$ & $6.1 \pm 0.1$ \\
\hline
\end{tabular}

* The error in the estimation of the transfer coefficient was not estimated. This error would be propogated into the error for both $j$ and $\beta$. Stability constants and ligand numbers for glycine and humic acid complexes are for pH 6.8 .

$\dagger$ The half-peak width varied and. therefore, the transfer coefficient was not a constant. No estimates of $j$ or $\beta$ were made.

obtained by DPP and DPASV using the Lingane equation only if both the-anodic and cathodic processes were irreversible to the same extent-clearly an extremely unlikely circumstance. When the same result is calculated by both DPP and DPASV it must be assumed that not only is the value of the equilibrium constant correct, but also the electrochemical processes and complexation are rapid. Furthermore, DPP peaks approximated the theoretical half-peak width of $45.5 \mathrm{mV}$ for a reversible reaction (Parry and Osteryoung, 1965), which further substantiates the reversibility of the reactions.

In applying the Lingane equation to the determination of stability constants by ASV, Bradford (1973) noted the requirement that the reaction must be rapid. Because his experimental value was in good agreement with published results, he concluded both that the reaction was fast and that his value for the stability constant was correct. In the present study no such comparison with literature data is necessary due to the previously discussed ability to validate results by comparing DPP to DPASV and by measuring half-peak width. Such a capability becomes most important when a stability constant for the complex being studied has not been reported previously.

In developing their $\mathrm{pH}$ dependent model for the chemical speciation of copper, zinc, cadmium and lead in seawater, Zirino and Yamamoto (1972) could find no stability constants reported for the lead carbonate ion pair. Based on the method of Garrels and Christ (1965) of estimating stability constants from solubility products and electronegativities, they estimated the logarithm of the stability constant for $\mathrm{PbCO}_{3}^{\circ}$ to be 7.5 . In a preliminary research report, Bilinski and Stumm (1973) reported 6.4 as the log of the stability constant for the ion pair. This was based on ASV measurements, but with no confirmation of the result or test that the reaction was fast. The present measurements of the stability constant therefore validate that of Bilinski and Stumm.

\section{Copper}

Data for the variation of copper peak potential with $\mathrm{pH}$ and total alkalinity showed a similar pattern for that of lead (Fig. 8). A strong dependence on pH with separate curves obtained for each of the alkalinities investigated was apparent. Therefore the potentials for both the DPP and DPASV copper peaks were plotted (Fig. 10) as a function of the carbonate ion concentration. Two separate linear segments are discernable for both the DPP and DPASV data.

The two linear portions for each analytical method were analyzed by least squares regression analysis. The linear portion extending from approximately $10^{-6}-10^{-4} \mathrm{M}$ carbonate ion would be included in the $\mathrm{pH}$ range $7.3-9.4$ for a water having a total alkalinity of 0.001 equiv $1^{-1}$. Thus, this complex might be expected to be quite significant for many natural water systems since many natural waters have alkalinities and $\mathrm{pH}$ ranges similar to this. The complex was calculated to have 0.99 carbonate per copper by DPASV measurement and 0.93 carbonate per copper by DPP measurement (Table 1 ). The standard errors for both measurements were 0.04 . The logarithm of the stability constant and its standard error was calculated as $6.1 \pm 0.2$ for DPASV and $5.7 \pm 0.2$ for DPP.

It should be noted that these values for the stability constant are significantly lower than the value of 6.77 for $\mathrm{CuCO}_{3}^{\circ}$ determined by Silman (1958) and reported 


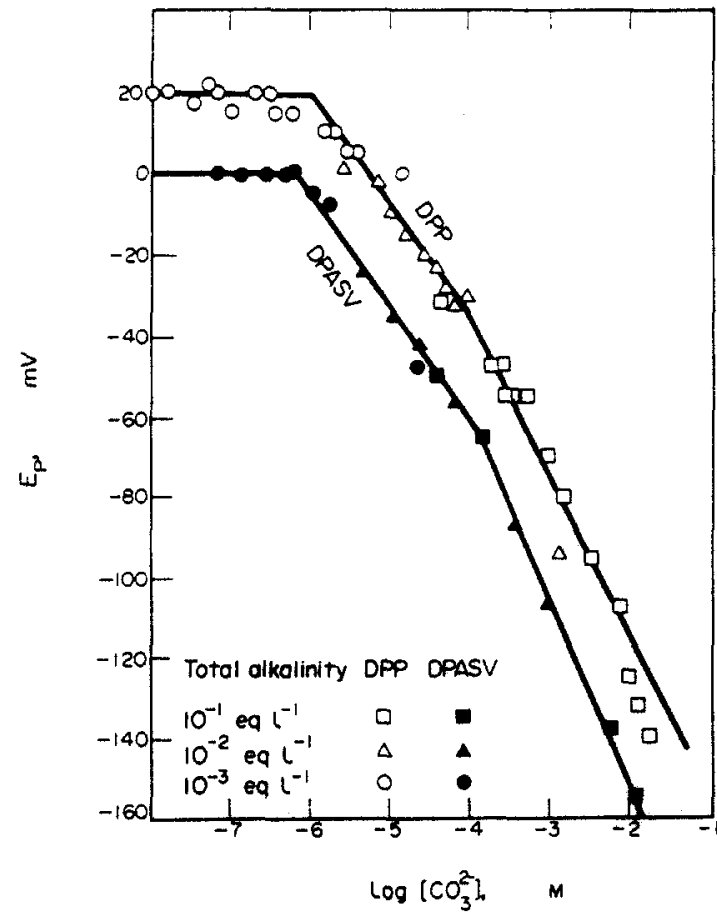

Fig. 10. Variation of DPP and DPASV peak potentials as a function of carbonate ion concentration for $2.5 \times 10^{-6} \mathrm{M}$ copper.

by Schindler (1967). When that value was used by Zirino and Yamamoto (1972), $\mathrm{CuCO}_{3}^{0}$ was predicted to form $30 \%$ of the copper at $\mathrm{pH} 7.0$ but less than $1 \%$ at $\mathrm{pH}$ 9. The dominant species in seawater was predicted to be $\mathrm{Cu}(\mathrm{OH})_{2}^{0}$; the logarithm of the stability constant was reported to be 14.3. Use of the present values for the stability constant for $\mathrm{CuCO}_{3}^{0}$ would only decrease the importance of this species relative to others such as $\mathrm{Cu}(\mathrm{OH})_{2}^{0}$.

It was anticipated that the linear line segments present at higher concentrations of carbonate ion were due to the formation of the $\mathrm{Cu}\left(\mathrm{CO}_{3}\right)_{2}^{2-}$ ion. However, when the slopes of the lines were determined, the corresponding ligand numbers 1.55 for DPASV and 1.63 for DPP were far too low to be considered those relating to the $\mathrm{Cu}\left(\mathrm{CO}_{3}\right)_{2}^{2-}$ ion.

Even though data for the high levels of carbonate were principally obtained using $10^{-1}$ equiv $l^{-1}$ alkalinity samples, several observations were made on $10^{-2}$ equiv $l^{-1}$ alkalinity samples at high $\mathrm{pH}$ values. When plotted vs $\mathrm{pH}$, the data for each $\mathrm{pH}$ were linear. However, different lines were obtained for different alkalinities, indicating that the complex was not a simple hydroxide species. In addition to the low values for the ligand number, the values for the logarithm of the stability constant by DPASV and DPP of 8.2 and 8.1, respectively, are significantly lower than the 10.0 value determined by Silman (1958). Therefore, the identity of this complex cannot be presently stated, although a carbonate-bicarbonate complex might explain the results. Such complexes have recently been studied by Odier and Plichon (1971) using a.c. polarography.
It is important to note that. irrespective of the exact nature of the complex. it may be assumed that DPP and DPASV can be used to determine its stability constant since the present study has demonstrated that the same value is obtained for anodic as well as cathodic processes.

\section{Cadmium and zinc}

As previously noted, variation in the alkalinity had a smaller effect on both the cadmium and zinc analyses than it did in the copper and lead analyses. In addition, the $\mathrm{pH}$ was shown to influence the cadmium system to a much smaller extent than any of the others. In addition to these observations being true for the previously discussed variations of peak current with $\mathrm{pH}$, they also help explain the variation of $E_{p}$ with $\mathrm{pH}$ and alkalinity.

In the case of cadmium, a virtually invariant $E_{p}$ was obtained irrespective of $\mathrm{pH}$ or alkalinity. Such behavior indicates that neither hydroxy nor carbonato complexes of cadmium have any appreciable existence within the range of conditions investigated.

For zinc a large potential shift occurred at the highest values of $\mathrm{pH}$ investigated for the $10^{-1}$ equiv $1^{-1}$ total alkalinity solution. This cathodic shift, which amounted to $150 \mathrm{mV}$ when the $\mathrm{pH}$ was raised from 8.05 to 9.7 , had the largest change above $\mathrm{pH} 9$ which was the same region in which the peak current was found to increase. Although the complex was not identified, it must contain carbonate since the shift occurred only at the highest alkalinity investigated.

\section{DEPENDENCE OF $E$, ON ORGANIC LIGAND CONCENTRATION}

\section{Glycine}

Metal glycinate stability constants were determined both by DPP and DPASV. In both cases the medium was $0.1 \mathrm{M}$ in $\mathrm{NaHCO}_{3}$ and was maintained at $\mathrm{pH}$ 6.8. Although a smaller fraction of the glycine is capable of complexation at this $\mathrm{pH}$ than at higher $\mathrm{pH}$, this $\mathrm{pH}$ simulates natural water conditions more closely than does a quite basic value. Similarly a solution containing carbonate was more realistic than one from which all other ligands were excluded.

Samples containing lead, cadmium or zinc at $2.5 \times$ $10^{-6} \mathrm{M}$ showed no shift in peak potential even when the total glycine concentration was as high as $4.8 \times$ $10^{-4} \mathrm{M}$. This is an indication that the stability of the metal hydroxide or carbonate complexes are greater than that of the metal glycine complexes under the experimental conditions. Under these conditions no complexation with glycine takes place; glycine is ineffectual as a ligand. Although stability constants could not be computed for these complexes, this result is instructive in illustrating behavior which might occur in the investigation of ligands in environmental matrices.

A frequent problem is to predict the behavior of a constituent added to the environment. Concern has been expressed relative to the effect of adding NTA, 
citrate or other replacements for phosphate in detergents. Even when the stability constants for the complexes of interest are known, our lack of knowledge regarding levels of naturally occurring ligands and their stability constants with the metals under consideration prevents prediction of the effect of such additions. We are even less able to predict the effect of additions of ligands such as algal metabolites or sewage whose structures are uncharacterized and whose stability constants have not been measured. By determining whether a peak shift occurs on addition of the ligand of interest, a rapid assessment of whether the added ligand significantly complexes the trace metal can be made.

The copper peak for both DPP and DPASV did shift when glycine was added to the bicarbonate-containing sample. This indicates that the copper-glycinate complex is more stable than is the copper carbonate complex under these conditions. Besides shifting the peak potential, addition of glycine caused a decrease in the peak current. The decrease was approximately $10 \%$ indicating that the copper-glycinate complex is labile and that its diffusion coefficient is similar in magnitude to both the inorganic complex of copper initially present and to that for the hydrated copper ion.

Although plots of $E_{p}$ vs log [glycine] are linear for both DPP and DPASV, the two lines are not parallel (Fig. 11). This can be best seen by comparison of the curves in Fig. 11 to those in Fig. 10. In the absence of ligand the DPP peak potential is anodic to that for DPASV; in the presence of glycine, the DPP peak is cathodic to the DPASV peak. Therefore, the two lines must have crossed.

For both the DPP and the DPASV data sets, the peaks are wider in the presence of glycine than in its absence. The broadened peaks are a result of the irreversibility of the electrochemical reaction. The ratio of the peak width for a reversible reaction to that for the irreversible reaction was used as the measure of the transfer coefficient $\alpha$ (Ernst et al., 1974). Since the peaks had the same half-width at all glycine concentrations, the degree of electrochemical reversibility was constant and consequently the Subrahmanya modification [equation (4)] of the Lingane

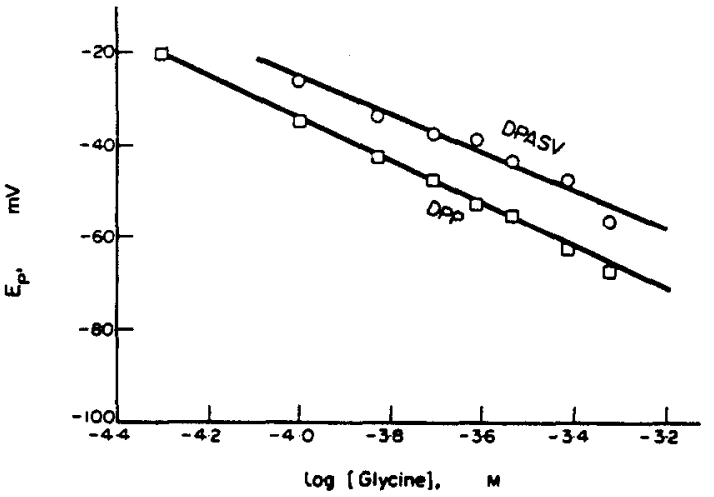

Fig. 11. Variation of DPP and DPASV peak potentials as a function of glycine concentration for $2.5 \times 10^{-6} \mathrm{M}$ copper at $\mathrm{pH} 6.8$.

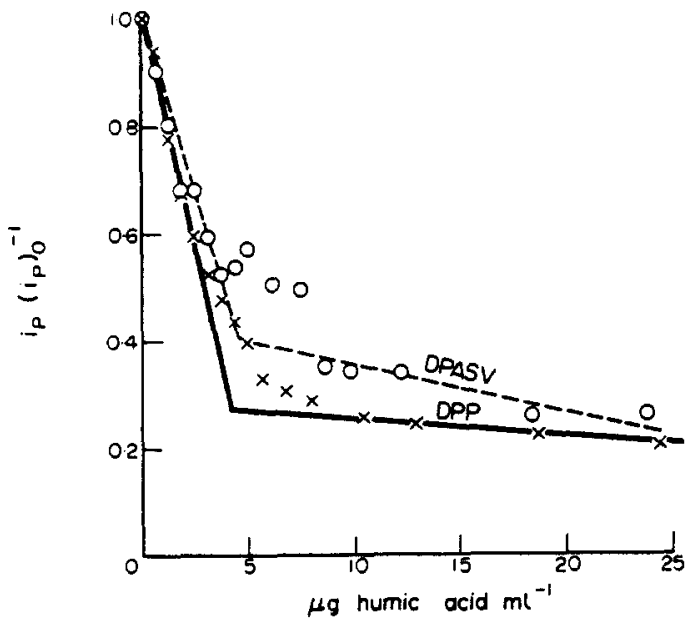

Fig. 12. Titration of $2.5 \times 10^{-6} \mathrm{M}$ lead with humic acid. Total alkalinity was $10^{-3}$ equiv $\mathrm{I}^{-1}$ and $\mathrm{pH}$ was 6.8 . Current measurements were normalized to current values in the absence of humic acid. Current and concentration values were corrected for sample dilution.

equation could be applied. Using the $\alpha$ values of 0.79 for DPP and 0.93 for DPASV, the logarithm of the stability constant was computed to be 6.4 and 5.9. respectively (Table 1). However, the ratio of the glycinate to the total glycine concentration at pH 6.8 was $10^{-3.1}$, based on values of 9.87 and 2.35 for the $p K_{a} s$. When this value was used to correct the stability constant for the proportion of the glycine capable of complexation, the logarithm of the stability constant was increased by 3.1 and values of 9.5 for DPP and 9.0 for DPASV were obtained.

Although quite similar results for both techniques were obtained after correction for the reversibility of the system. the results for the stability constant are somewhat higher than values reported by Sillen and Martell (1964) which range from 8.0 to 8.6. Neither the reason for this nor for the ligand number exceeding one ( 1.24 by DPP and 1.28 by DPASV) could be easily explained. We suspect the formation of some diglycine complex at higher ligand concentrations. This was corroborated by recalculation of the equilibrium constant neglecting the highest concentrations of glycine for the DPASV measurement and the highest two concentrations for the DPP measurement. This resulted in values for $\log \beta$ of 9.3 and 8.3 and values for $j$ of 1.18 and 1.11 by DPP and DPASV, respectively.

\section{Humic acid}

Addition of humic acid to copper, lead or zinc solutions resulted in a decreased DPP or DPASV signal. At high concentrations of humic acid the signal was reduced to $10-20 \%$ of that measured in the absence of humic acid (Fig. 12). This signal decrease did not appear to be due to the precipitation of metal humate which we found to precipitate at higher concentrations of metal.

From the value of the concentration of humic acid at the end point of the titration curve, we calculated the equivalent weight of humic acid. For both copper 
and lead by both DPP and DPASt. identical values

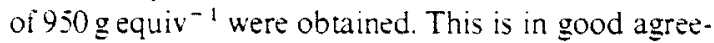
ment with the values reported by Visser and Mendel (1971). This procedure offers an alternative to those presently used.

Based on the end point of the titration curve. concentrations of humic acid in excess of $1: 1$ stoichiometry were used for stability constant determinations. The concentration of humic acid was expressed in m-equiv $\mathrm{I}^{-1}$ and the peak potentials were plotted vs the logarithm of these concentrations (Fig. 13). For each metal two linear segments were apparent by each technique. In no case were the electrochemical reactions reversible. However, constant half-peak widths for lead by DPP and DPASV and for copper by DPP permitted estimation of the $x$ values given in Table 1. Copper determinations by DPASV showed that the peak half-width varied and. therefore, the data were not treated further.

The stability constants determined from the DPP and DPASV data for the lead-humic acid system were quite different. In addition, the values of the ligand number are also quite different as determined by the two techniques. Since the same equivalent weight was determined by both methods and used to calculate the excess humic acid concentration. the ligand number resulting from the modified Lingane formula should have been equal to 1 . Because this was not the case. and because different values for log $\beta$ and $j$ were obtained by the two techniques, it can be implied that the necessary conditions for the application of the formula were not met. With the exception of electrochemical reversibility, all the conditions previously listed as having to be met for the Lingane equation must also be met for the modified equation. The decrease in signal accompanying complexation may be indicative of the non-labile character of a soluble complex or to the formation of a colloidal metal humate. Therefore, the system is not truly amenable to treatment by this means of data analysis.

In addition to the obvious non-lability of the

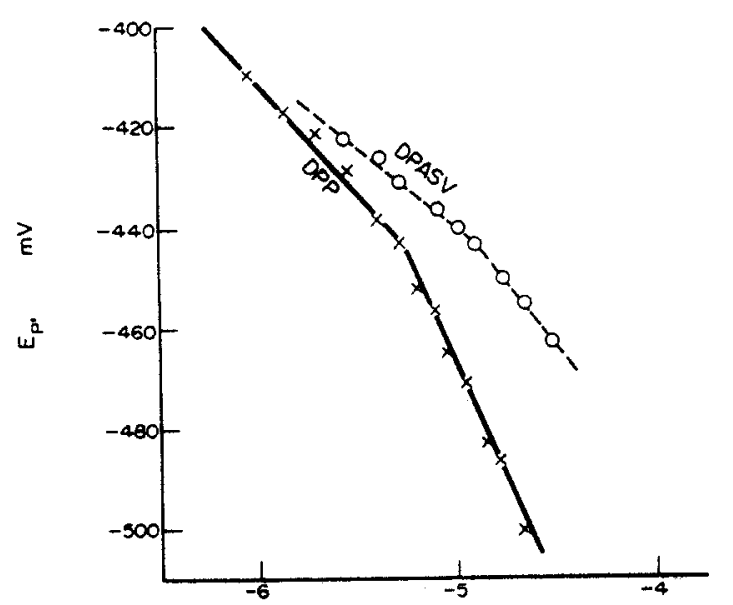

$\log [H A], \quad$ eq $l^{-1}$

Fig. 13. Variation of DPP and DPASV peak potentials as a function of humic acid concentration for $2.5 \times 10^{-6} \mathrm{M}$ lead at pH 6.8 . metal-humic acid complex. the concentration of humic acid at the electrode surface may not be the same as in the bulk of the solution. When humic acid was added to a solution which had not been stripped of oxygen. the peak potential for oxygen shifted cathodically. This shift may indicate that the reversibility of oxygen reduction is decreased because humic acid is adsorbed at the electrode surface. Because the concentration of humic acid in the diffusion layer is unknown. application of conventional electroanalytical techniques to the calculation of stability constants is not possible.

\section{CONCLLSIONS}

This study has shown that cathodic and anodic voltammetric techniques can be used to characterize trace metal interactions in aquatic environments. Metal complexation as a function of $\mathrm{pH}$ and alkalinity could be detected easily by changes in the peak current and this technique was used to verify existing equilibrium models.

Stability constants were determined from shifts in the peak potential using the Lingane equation. Although this method has usually been used only for measurements involving reversible electrode processes, by the inclusion of the transfer coefficient in the Lingane equation, it was possible to extend the method to irreversible systems. For both the reversible and irreversible cases the applicability of the data treatment could be ascertained by comparison of DPP and DPASV results. Obtaining the same result by cathodic and anodic measurement implies that the result is correct.

At present it would appear that accurate measurement of stability constants involving ligands adsorbed at the electrode surface is not possible. This should not, however, preclude the use of electrochemical measurements in other situations.

Acknowledgements-R. Ernst was supported as a post-doctoral fellow by the Stiftung für Stipendien auf dem Gebiete der Chemie, Basel, Switzerland. This research was partially supported by NIH Grant 5S01-RR05447-11 (Project 133).

\section{REFERENCES}

Ackermann H. and Schwarzenbach G. (1952) Komplexone XXII. Die Kinetik der Komplexbildung: Der Austausch des $\mathrm{Y}^{-+}$zwischen $\mathrm{Cd}^{+2}$ und $\mathrm{Cu}^{+2}$. Helv, chim. Acta 35. $485-497$.

Beck M. T. (1970) Chemistry of Complex Equilibria. Van Nostrand Reinhold. New York.

Bilinski H. and Stumm W. (1973) Pb(II)-species in natural waters. EAWAG News 1, 2-3.

Bradford W. L. (1973) The determination of a stability constant for the aqueous complex $\mathrm{Zn}(\mathrm{OH})_{2}^{0}$ using anodic stripping voltammetry. Limnol. Oceanogr. 18, 757-762.

Cheng M. H.. Patterson J. W. and Minear R. A. (1975) Heavy metals uptake by activated sludge. $J$. Wat. Pollut. Control Fed. 47. 362-376.

Crow D. R. (1969) Polarography of Metal Complexes. Academic Press. New York.

Crow D. R. and Westwood J. V.(1965) The study of complexed metal ions by polarographic methods. Quart. Rev. Chem. Soc. 19. 57-76. 
DeFord D. D. and Hume D. N. (1951) The determination of consecutive formation constants of complex ions from polarographic data. J. Am. chem. Soc. 73, 532l-5325.

Eriksson L. (1953) The complexity constants of cadmium chloride and bromide. Acta chem. scand. 7, 1146-1154.

Ernst R.. Allen H. E. and Mancy K. H. (1974) Differential pulse polarographic and differential pulse anodic stripping voltammetric determination of complexes of metals which are electrochemically reversible or irreversible. Submitted for publication.

Garrels R. M. and Christ C. L. (1965) Solutions, Minerals, and Equilibria. Harper and Row. New York.

Hem J. D. and Durum W. H. (1973) Solubility and occurrence of lead in surface water. J. Am. Wat. Wks. Ass. 65. $562-568$.

Heyrovsky J. and Ilkovic D. (1935) Polarographic studies with the dropping $\mathrm{Hg}$ electrode-II: The absolute determination of reduction and depolarization potentials. Coll. Caech. chem. Comm. 7, 198-214.

Lingane J. J. (1941) Interpretation of the polarographic waves of complex metal ions. Chem. Rev. 29, 1-35.

Mancy K. H. (1972) Trace metal characterization by anodic stripping voltammetry. 6th Int. Wat. Pollut. Res., Session 4. paper 7.10 pp.

Martell A. E. and Calvin M. (1952) Chemistry of the Metal Chelate Compounds. Prentice-Hall, New York.

Odier $M$. and Plichon V. (1971) Le cuivre en solution dans l'eau de mer: forme chimique et dosage. Analytica chim. Acta 55. 209-220.

Osteryoung J. G. and Osteryoung R. A. (1972) Pulse polarographic analysis of toxic heavy metals. Am. Lah. 4. 7. $8-16$.

Parry E. P. and Oldham K. B. (1968) Electrochemistry of palladium(II) ion in ammonia and pyridine media. dnaly. Chem. 40, 1031-1036.

Parry E. P. and Osteryoung R. A. (1965) Evaluation of analytical pulse polarography. Analyt. Chem. 37. 1634 1637.

Ringbom A. and Eriksson L. (1953) The evaluation of complexity constants from polarographic data. Acta chem. scand. 7. 1105-1111.

Roberts R. F. and Allen H. E. (1972) The control of $\mathrm{pH}$ and total alkalinity or total carbonate in aquatic bioassays. Trans. Am. Fish. Soc. 101, 752-756.

Rossotti F. J. C. and Rossotti H. (1961) The Determination of Stuthility Constants. McGraw-Hill, New York.
Schindler P. W. (1967) Heterogeneous equilibria involving oxides. hydroxides, carbonates, and hydroxide carbonates. Equilibrium Concepts in Natural Waters (Edited by Gould R. E.). Advances in Chemistry Series No. 67, pp. 196-221. American Chemical Society, Washington.

Schnitzer M. and Khan S. U. (1972) Humic Substances in the Environment. Marcel Dekker. New York.

Schwarzenbach G., Gut R. and Anderegg G. (1954) Komplexone XXV. Die polarographische Untersuch von Austauschgleichgewichten. Neue Daten der Bildungskonstanten von Metallkomplexen der Äthylendiamintetraessigsäure und der 1.2-Diaminocyclohexan-tetraessigsäure. Helt. chim. Acta 37, 937-956.

Siegerman H. and O'Dom G. (1972) Differential pulse anodic stripping of trace metals. Am. Lab. 4, 6, 59-68.

Silman J. R. (1958) Ph.D. Thesis. Harvard Univ.. Cambridge. Mass.

Sillen L. G. and Martell A. (1964) Stability constants of metal-ion complexes. Spec. Pub. No. 17. The Chemical Society of London.

Stevenson F. J. and Ardakani M. S. (1972) Organic matter reactions involving micronutrients in soils. Micronutrients in Agriculture, pp. 79-114. Soil Science Society of America. Madison. Wisconsin.

Stumm W. and Bilinski H. (1973) Trace metals in natural waters; difficulties of interpretation arising from our ignorance on their speciation. Adtances in Water Pollution Research, pp. 39-49. Pergamon Press. New York.

Subrahmanya R. S. (1960) Polarography of ethanolamine complexes of iron. cadmium, nickel, cobalt, copper, lead and zinc. Advances in Polarography (Edited by Longmuir I. S.), Vol. 2, pp. 674-693. Pergamon Press. New York.

Tamamushi R. and Tanaka N. (1949) Fundamental studies on the current-voltage curve in polarography-II: Derivation of the activation-controlled polarographic waves of simple metal ions from the standpoint of chemical kinetics. Bull. chem. Soc. Jap. 22, 227-236.

Twork J. V. (1974) Unpublished results. Environmental Chemistry Laboratory, School of Public Health. The University of Michigan, Ann Arbor.

Visser S. A. and Mendel H. (1971) X-ray diffraction studies on the crystallinity and molecular weight of humic acids. Soil Biol. Biochem. 3, 259-265.

Zirino A. and Yamamoto S. (1972) A pH dependent model for the chemical speciation of copper, zinc, cadmium. and lead in seawater. Limnol. Oceanogr. 17, 661-671. 